\title{
Short communication: Lack of intramammary niche recolonization during a sanitation program for the contagious mastitis pathogen Staphylococcus aureus genotype B
}

\author{
C. Sartori, ${ }^{\star} †$ V. Perreten,‡ I. Ivanovic, ${ }^{*}$ M. C. Härdi-Landerer,† and H. U. Graber ${ }^{* 1}$ \\ *Food Microbial Systems, Group Microbiological Safety of Foods of Animal Origin, Agroscope, 3003 Berne, Switzerland \\ †Institute of Agricultural Sciences (IAS), Animal Physiology Group, ETH Zurich, 8092 Zurich, Switzerland \\ łInstitute of Veterinary Bacteriology, Vetsuisse Faculty, University of Bern, 3012 Bern, Switzerland
}

\begin{abstract}
In Switzerland, sanitation programs of dairy herds infected with the contagious mastitis pathogen Staphylococcus aureus genotype B (GTB) have been established for several years. In recent years, Streptococcus uberis and non-aureus staphylococci have emerged as the bacteria most frequently isolated from bovine milk samples. The latter cause subclinical mastitis, and some species are more persistent or pathogenic than others. The present study aimed to investigate the developments in the intramammary colonization spectrum of 5 dairy herds undergoing a sanitation program for Staph. aureus GTB. We collected single-quarter milk samples aseptically from all lactating cows at 3-mo intervals during the sanitation period; after classical bacteriological analysis, MALDI-TOF mass spectrometry was used to identify the isolates to the species level. Non-aureus staphylococci were found to be the bacterial group most frequently occurring on the selected farms, with Staphylococcus chromogenes and Staphylococcus xylosus being predominant. The present study demonstrated that GTB-infected cows treated with antibiotics lacked systematic recolonization with other bacteria during herd sanitation for the contagious Staph. aureus GTB.
\end{abstract} Key words: dairy cow, intramammary colonization, non-aureus staphylococci, MALDI-TOF

\section{Short Communication}

The present study is part of a sanitation study for Staphylococcus aureus genotype B (GTB; Sartori et al., 2018), which is one of the most prevalent and contagious genotypes of Staph. aureus circulating in Switzerland and typically causes herd problems (Fournier et al., 2008; Graber et al., 2009). All other Staph. aureus genotypes are responsible for sporadic

Received December 28, 2017.

Accepted May 6, 2018.

${ }^{1}$ Corresponding author: hansulrich.graber@agroscope.admin.ch infections in single quarters and cows (Fournier et al., 2008; Graber et al., 2009). Therefore, a sanitation program of Staph. aureus GTB-positive dairy herds was established and performed in Switzerland (Sartori et al., 2018). The progressive eradication of Staph. aureus GTB from infected cows may open a new intramammary biological niche, which could be recolonized by new bacteria, potentially representing a new udder health concern for the sanitized herds. In particular, non-aureus staphylococci (NAS) and Streptococcus uberis are among the bacteria most frequently isolated from the milk of cows with subclinical IMI (Bradley, 2002; Taponen and Pyörälä, 2009; De Visscher et al., 2015) and might therefore be possible recolonizers. Although NAS are generally considered less pathogenic than Staph. aureus, they can contain virulence factors, leading to problems such as toxin production, increased adhesion to the bovine mammary gland epithelium, and biofilm formation (Taponen and Pyörälä, 2009; Vanderhaeghen et al., 2014). Furthermore, some NAS species (e.g., Staphylococcus chromogenes, Staphylococcus simulans) were shown to persist in the mammary gland of infected cows causing increased SCC (Fry et al., 2014), and Staphylococcus epidermidis and Staphylococcus haemolyticus were shown to be the species most resistant to several antibiotics typically used for the treatment of IMI in Europe, including penicillin, methicillin, macrolides, and aminoglycosides (Taponen and Pyörälä, 2009; Frey et al., 2013; Taponen et al., 2016). The use of antibiotics for the sanitation of GTB might represent, therefore, a risk of selecting for IMIassociated bacteria, particularly NAS. The aim of the present study was to investigate the developments in the bacterial intramammary colonization spectra of 5 dairy herds, which participated in a sanitation program for Staph. aureus GTB.

Isolates were obtained between October 2013 and September 2017 during the sanitation study performed by Sartori et al. (2018), which included 19 initially Staph. aureus GTB-positive dairy herds. During the sanitation study, farmers had to follow a restricted 
number of mandatory milking procedures. The most important one was the keeping of a strict and correct milking order based on the GTB status of the cows in the herd. Only cows infected with Staph. aureus GTB were systematically subjected to antibiotic treatment during lactation or the dry cow period, or both, whereas IMI caused by NAS remained systematically untreated. Cows with acute or peracute mastitis were treated by the private veterinarian and were excluded from the study. The GTB-positive cows not responsive to antibiotic therapy were recommended to be culled as long as they were not pregnant.

To reduce laboratory work, 5 herds were selected for the present study, resulting in 2,640 milk samples. Aseptically collected, single-quarter milk samples of all lactating cows were bacteriologically evaluated at the first farm visit and 3 additional times at 3-mo intervals (corresponding to the samplings $1,3,6$, and 9). The within-herd prevalence of Staph. aureus GTB was determined for the samplings 1, 3, 6, and 9 (Table 1) by analyzing composite milk samples of each cow by real-time quantitative PCR for the unique target gene $a d l b$ as described by Sartori et al. (2017). The adlb gene is highly sensitive and specific for Staph. aureus GTB both at the analytical and the diagnostic level, enabling the very specific detection of the genotype of interest (Sartori et al., 2017). Bacteriological analysis was performed according to the Laboratory Handbook on Bovine Mastitis of the National Mastitis Council (NMC, 1999). In brief, $10 \mu \mathrm{L}$ of milk were plated on sheep blood agar (BA) plates (Biomérieux Suisse SA, Geneva, Switzerland), and bacterial cultures (morphology, hemolysis, catalase activity, Gram stain) were evaluated after 24 and $48 \mathrm{~h}$ of aerobic incubation at $37^{\circ} \mathrm{C}$. Corynebacterium spp. were identified at the genus level based on typical growth after $48 \mathrm{~h}$, typical morphology on BA, and catalase activity (NMC, 1999). All other bacterial species than Corynebacterium spp. showing a growth of at least $10^{3} \mathrm{cfu} / \mathrm{mL}(10 \mathrm{cfu} / 10 \mu \mathrm{L})$ on BA were isolated and conserved in skim milk at $-20^{\circ} \mathrm{C}$ until they were analyzed by MALDI-TOF MS as described by Dolder et al. (2017). In brief, a toothpick was used to directly smear a small amount of each colony onto the target plate (Bruker Daltonics GmbH, Bremen, Germany), followed by adding $1 \mu \mathrm{L}$ of $70 \%$ formic acid and $1 \mu \mathrm{L}$ of $\alpha$-cyano-4-hydroxycinnamic acid-matrix (Bruker Daltonics $\mathrm{GmbH}$ ). The MALDI-TOF MS analysis was then performed using the Microflex LT (Bruker Daltonics $\mathrm{GmbH}$ ) using an expanded database (Dolder et al., 2017). In this expanded library, 2 species were found to be related to Staphylococcus warneri and to Staphylococcus devriesei by $16 \mathrm{~S}$ rRNA and rpoB or dnaJ sequences and were considered as Staph. warneri-like and Staph. devriesei-like, respectively (Dolder et al., 2017).
Isolates with scores $\geq 2.0$ were identified at the species level according to the manufacturer's guidelines (www .bruker.com).

Data were expressed as counts or frequencies or presented as median, minimum, and maximum. Statistical data evaluation was performed using the Systat 13.1 software (Systat Software, San Jose, CA).

An overview of the Staph. aureus GTB sanitation results is provided in Table 1; during the observation period of 9 mo, herds 12, 15, and 19 were completely sanitized. Farm 11 still had 2 cows infected at sampling 9 (5\% of the cows), and farm 16 could not be sanitized until the end of the sanitation program because 6 cows (21\%) were still GTB-positive at sampling 9 (Table 1). Cows infected with other genotypes of Staph. aureus were exclusively found on farms 11 and 15 during the sanitation study (Table 1). Corynebacterium spp. were found on all farms at all samplings. Streptococcus uberis $(\mathrm{n}=23)$ was isolated at low rates on all farms, whereas other Streptococcus spp. were found in single quarters and farms (Table 2). Enterobacteriaceae $(\mathrm{n}=9)$ were found in single quarters on 4 farms (Table 2). Among the category others $(\mathrm{n}=42)$, Aerococcus viridans $(\mathrm{n}=$ 16) was isolated at low rates on 4 farms, whereas all other species were rarely detected in single quarters and farms (Table 2).

The group of species the most frequently isolated during the present sanitation study were NAS. Out of 306 NAS isolates, 12 different species were found on the selected farms (Table 2). Five main species occurred more frequently during the observation time (Table 2), including Staphylococcus xylosus $(\mathrm{n}=134)$, Staph. chromogenes $(\mathrm{n}=82)$, and Staph. haemolyticus $(\mathrm{n}=13)$, which were found on almost all farms. In contrast, Staphylococcus sciuri $(\mathrm{n}=45)$ was only found on farms 11 and 19, with 42 isolates (93\%) found on farm 11 (Table 2). Similarly, Staph. simulans was mainly observed on farm 19 (8 out of 9 isolates). Other NAS were also found on the different farms, but at low frequencies (Table 2). Each herd was characterized by a farm-specific intramammary colonization pattern: Staph. xylosus and Staph. sciuri were the bacteria mostly found on farm 11, particularly at 1st sampling (Table 2, Figure 1). On farm 12, Staph. chromogenes and Staph. haemolyticus were predominant, whereas Staph. xylosus was the main NAS species on farm 15 (Table 2). Farm 16 was characterized by the presence of Staph. chromogenes and Staph. xylosus, and the same 2 species together with Staph. simulans were typical for farm 19 (Table 2). Considering the total NAS quarter prevalence per farm over the 9-mo observation period, a rather constant course was observed for farms 12 , 15 , and 16, with median values of 6 (range $=4-7 \%$ ), $10(4-14 \%)$, and $7 \%(4-9 \%)$, respectively (Figure 1). 


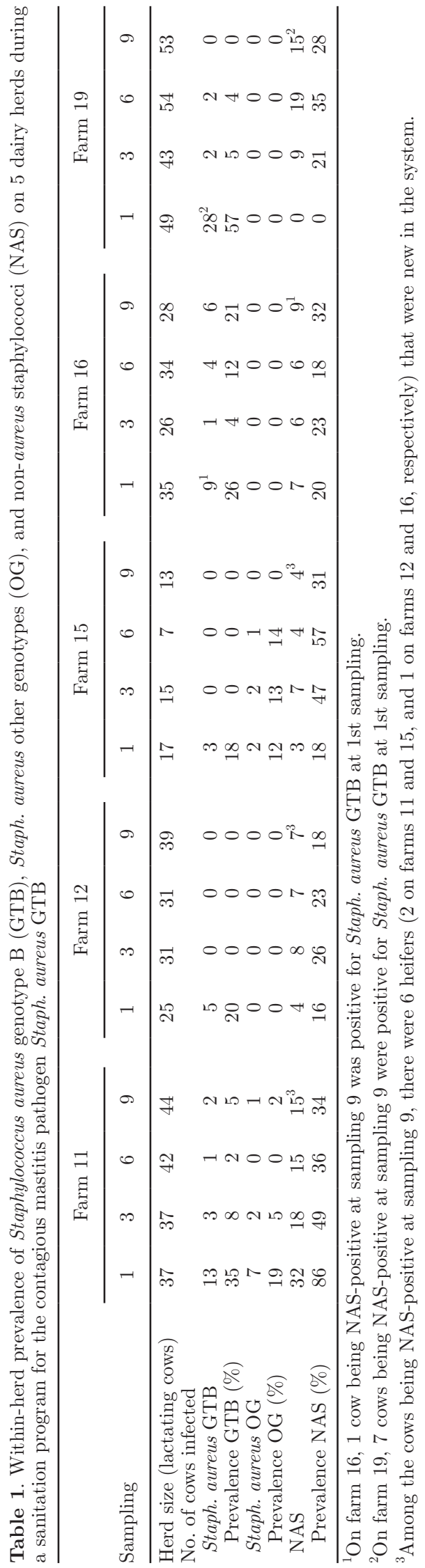

A singular pattern was observed for farm 11, which showed a strong decrease from sampling 1 to sampling 9 (55 to 10\%, respectively; Figure 1). On the other hand, an increase of the total NAS quarter prevalence was observed for farm 19, which reached a value of $11 \%$ at sampling 9 after having started with a prevalence of zero (Figure 1). Considering all farms, a convergence toward $10 \%$ was observed for the total NAS quarter prevalence at the end of the sanitation program (Figure 1).

To evaluate a possible association between the positivity for Staph. aureus GTB at a previous point in time, and colonization of previously GTB-positive cows by NAS, we traced back the GTB status of cows that were NAS-positive at the end of the sanitation program at sampling $9(\mathrm{n}=50$; Table 1$)$. Out of these 50 cows colonized with NAS, 8 were GTB-positive at 1st sampling, and 7 were from farm 19. The other 42 cows were GTB-negative before becoming infected with NAS at a later point in time and had never been treated with antibiotics during the sanitation time.

The present study shows that during and after GTB sanitation NAS are by far the most frequent IMI-causing bacteria, whereas Streptococcus spp., Enterobacteriaceae, and other bacteria play a minor role. The initial quarter NAS prevalence and its course was highly herd dependent, but it always reached a value of about $10 \%$ at the end of the sanitation program. In the case of farm 11 , we found a high NAS quarter prevalence $(55 \%)$ at first sampling that decreased over time to $10 \%$ (Figure 1, Table 2). This decrease was spontaneous and was not the consequence of antimicrobial treatment. It coincided, however, with the fact that an automatic milking system was replaced by a conventional milking parlor 2 wk before starting the sanitation program. In contrast to farm 11, no NAS were initially found on farm 19, but the total NAS prevalence ended up in $11 \%$ after 9 mo. In between, 3 farms had rather constant NAS prevalence over time, fluctuating around $10 \%$. Whereas in 4 farms we found no indication for recolonization of a probable intramammary niche opened by the eradication of Staph. aureus GTB, such a phenomenon could be supposed for farm 19 at first glance. Indeed, at sampling 9, seven initially GTB-positive and successfully treated cows were NAS-positive. At the same point in time, however, 8 further cows (initially GTB-negative) were NAS infected as well. These results clearly demonstrate that NAS infection on this farm was not a specific problem of previously GTB-positive cows, but a general one that was introduced by the farmer during sanitation.

The presence of an own, specific intramammary colonization pattern in each herd is in accordance with the results by Supré et al. (2011), who found that species 
SHORT COMMUNICATION: STAPHYLOCOCCI AND MASTITIS

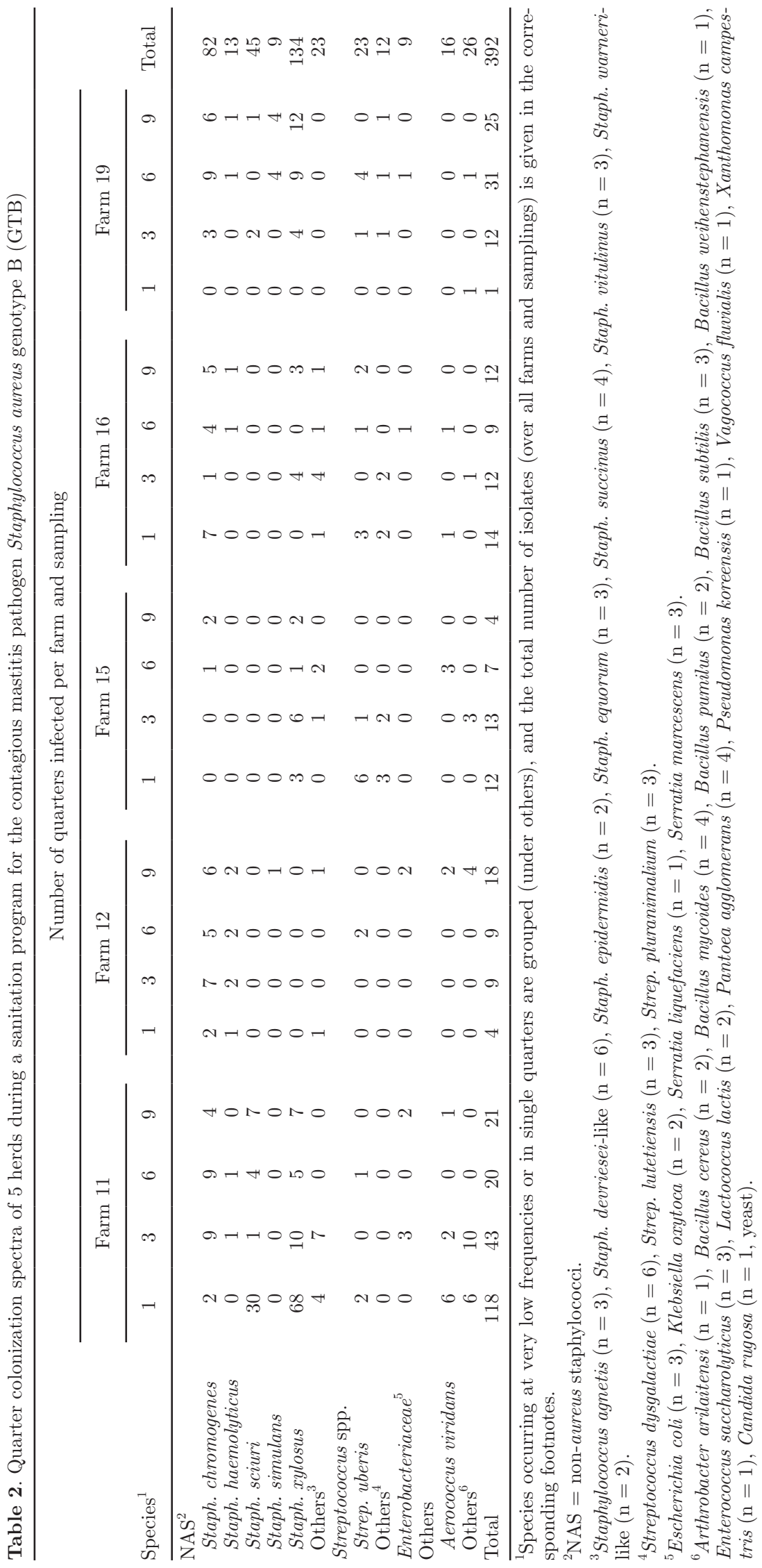




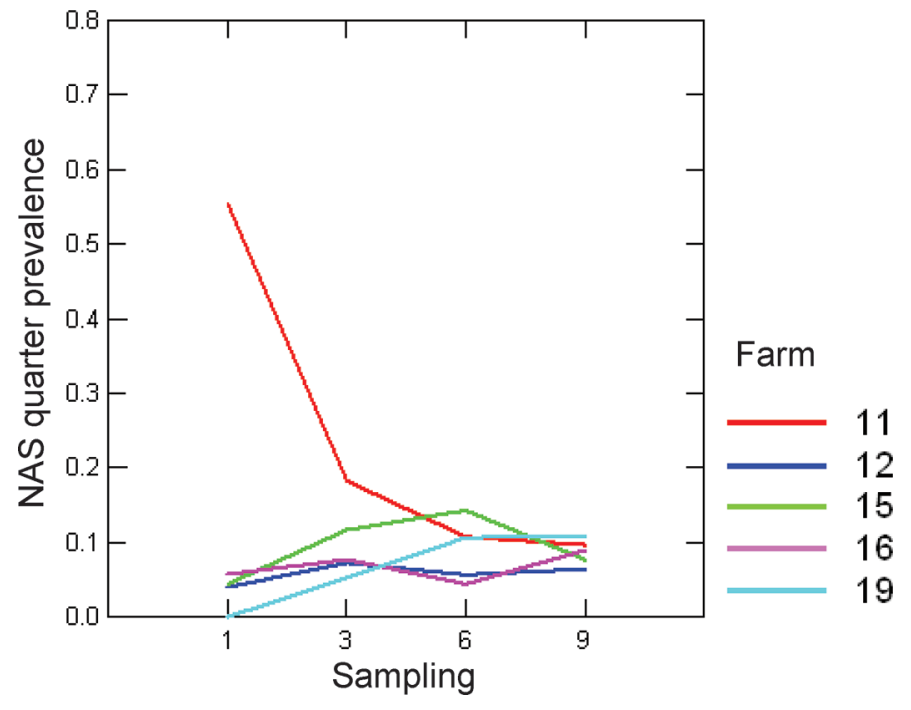

Figure 1. Quarter prevalence course of non-aureus staphylococci (NAS) in 5 herds participating to a sanitation program for the contagious mastitis pathogen Staph. aureus genotype B (GTB). The x-axis indicates the samplings, which were carried out at 3-mo intervals during the observation period. The y-axis reports the total NAS quarter prevalence (all species together). Different line colors highlight the different farms: red (farm 11), blue (farm 12), green (farm 15), pink (farm 16), and turquoise (farm 19).

distribution is herd-specific. With regard to the prevalence of different NAS species in mastitis milk samples, our results are in line with those reported in literature. Frey et al. (2013) also found Staph. xylosus, Staph. chromogenes, Staph. sciuri, and Staph. haemolyticus being the staphylococcal species most frequently isolated from Swiss bovine milk. Similar results were reported in both a Belgian and a Canadian study on bovine IMI (Supré et al., 2011; Fry et al., 2014). These findings are in line with our results and demonstrate, therefore, that the outcome of the present study corresponds to a standard situation that is independent on the GTB sanitation itself.

In conclusion, the present study demonstrated that GTB-infected cows treated with antibiotics remained free from recolonization with other bacteria during herd sanitation for Staph. aureus GTB. However, farmspecific factors may promote the recolonization of the mammary gland by NAS (particularly Staph. chromogenes) in some cases. Overall, Staph. xylosus and Staph. chromogenes were the bacteria the most frequently isolated from cow milk on the selected farms. In contrast, other NAS species and bacteria were rarely detected and, therefore, played a minor role as IMI pathogens in dairy herds undergoing sanitation for Staph. aureus GTB.

\section{ACKNOWLEDGMENTS}

We thank all farmers for their cooperation during our field study, and Alexandra Collaud (Institute of Veterinary Bacteriology, University of Bern, Switzerland) for technical assistance during MALDI-TOF MS analysis. The study was supported by a research grant of the Federal Office for Agriculture (FOAG, Berne, Switzerland).

\section{REFERENCES}

Bradley, A. J. 2002. Bovine mastitis: An evolving disease. Vet. J. 164:116-128.

De Visscher, A., S. Piepers, K. Supré, F. Haesebrouck, and S. De Vliegher. 2015. Short communication: Species group-specific predictors at the cow and quarter level for intramammary infection with coagulase-negative staphylococci in dairy cattle throughout lactation. J. Dairy Sci. 98:5448-5453.

Dolder, C., B. H. van den Borne, J. Traversari, A. Thomann, V. Perreten, and M. Bodmer. 2017. Quarter- and cow-level risk factors for intramammary infection with coagulase-negative staphylococci species in Swiss dairy cows. J. Dairy Sci. 100:5653-5663.

Fournier, C., P. Kuhnert, J. Frey, R. Miserez, M. Kirchhofer, T. Kaufmann, A. Steiner, and H. U. Graber. 2008. Bovine Staphylococcus aureus: Association of virulence genes, genotypes and clinical outcome. Res. Vet. Sci. 85:439-448.

Frey, Y., J. P. Rodriguez, A. Thomann, S. Schwendener, and V. Perreten. 2013. Genetic characterization of antimicrobial resistance in coagulase-negative staphylococci from bovine mastitis milk. J. Dairy Sci. 96:2247-2257.

Fry, P. R., J. R. Middleton, S. Dufour, J. Perry, D. Scholl, and I. Dohoo. 2014. Association of coagulase-negative staphylococcal species, mammary quarter milk somatic cell count, and persistence of intramammary infection in dairy cattle. J. Dairy Sci. 97:4876-4885.

Graber, H. U., J. Naskova, E. Studer, T. Kaufmann, M. Kirchhofer, M. Brechbühl, W. Schaeren, A. Steiner, and C. Fournier. 2009. Mastitis-related subtypes of bovine Staphylococcus aureus are characterized by different clinical properties. J. Dairy Sci. 92:1442-1451.

NMC (National Mastitis Council). 1999. Laboratory Handbook on Bovine Mastitis. Rev. ed. National Mastitis Council Inc., Madison, WI.

Sartori, C., R. Boss, M. Bodmer, A. Leuenberger, I. Ivanovic, and H. U. Graber. 2018. Sanitation of Staphylococcus aureus genotype B-positive dairy herds: A field study. J. Dairy Sci. 101:6897-6914. https://doi.org/10.3168/jds.2017-13937.

Sartori, C., R. Boss, I. Ivanovic, and H. U. Graber. 2017. Development of a new real-time quantitative PCR assay for the detection of Staphylococcus aureus genotype B in cow milk, targeting the new gene adlb. J. Dairy Sci. 100:7834-7845.

Supré, K., F. Haesebrouck, R. N. Zadoks, M. Vaneechoutte, S. Piepers, and S. De Vliegher. 2011. Some coagulase-negative Staphylococcus species affect udder health more than others. J. Dairy Sci. 94:2329-2340.

Taponen, S., S. Nykäsenoja, T. Pohjanvirta, A. Pitkälä, and S. Pyörälä. 2016. Species distribution and in vitro antimicrobial susceptibility of coagulase-negative staphylococci isolated from bovine mastitic milk. Acta Vet. Scand. 58:12-13.

Taponen, S., and S. Pyörälä. 2009. Coagulase-negative staphylococci as cause of bovine mastitis-Not so different from Staphylococcus aureus? Vet. Microbiol. 134:29-36.

Vanderhaeghen, W., S. Piepers, F. Leroy, E. Van Coillie, F. Haesebrouck, and S. De Vliegher. 2014. Invited Review: Effect, persistence, and virulence of coagulase-negative Staphylococcus species associated with ruminant udder health. J. Dairy Sci. 97:5275-5293. 